\section{Prevalence of retinopathy and associated risk factors among high- and low-risk patients with type 2 diabetes mellitus. $A n$ observational study}

\author{
Salem A. Alghamdi, MD, \\ Ayla M. Tourkmani, Pharm.D, PhD, \\ Turki J. Alharbi, MD, $A D C F$, \\ Abdulaziz Bin Rsheed, $M D, A D C F$, \\ Wedad H. Almadani, MSc, MPH.
}

\section{ABSTRACT}

Objectives: To assess the prevalence and risk factors of diabetic retinopathy (DR) in patients with type 2 diabetes mellitus (T2DM) of different risks, based on the level of glycated hemoglobin (HbA1c).

Methods: A cross-sectional study was conducted in in the chronic illness clinics in Saudi Arabia between January 2019 and February 2020. Data were extracted from 428 T2DM patients' medical records and random sampling were carried out using a ratio of 1:3, matched for gender and duration of DM. Patients with $\mathrm{HbAlc}$ level $\geq 9 \%$ were classified as 'high-risk' and HbA1c $\leq 7 \%$ as 'low-risk'. Retinopathy was confirmed by an ophthalmologist using fundus photography.

Results: The prevalence of DR in high-risk patient was $88.1 \%$ and $22.1 \%$ in low-risk patients. The prevalence of macular oedema was higher in the high-risk compared to low-risk patients ( $15.8 \%$ versus $4.9 \%, p<0.001)$. Patients' mean age was $61 \pm 11$ years and duration of diabetes was $13 \pm 7$ years. Hemoglobin Alc and low-density lipoprotein (LDL) levels were significantly higher in high-risk patients $(p<0.0001)$ in bivariate but not multivariate analysis.

Conclusion: High $\mathrm{HbAlc}$ and LDL levels were associated with DR risk. Further multicentre studies involving large samples are required to assess the risk factors associated with DR progression.

Keywords: type 2 diabetes mellitus, retinopathy, prevalence, risk factors

Saudi Med J 2021; Vol. 42 (6): 693-697 doi: 10.15537/smj.2021.42.6.20210016

$\mathrm{D}$ iabetes is a common chronic disease associated with micro- and macro- vascular complications. The global burden of diabetes has been rising, mainly type 2 (T2DM), it is anticipated to reach 578 million cases by 2030 , compared with 463 million cases in $2019 .{ }^{1}$ In respect of prevalence and incidence of diabetes in the Kingdom of Saudi Arabia, the International Diabetes Federation (IDF) ranked Saudi Arabia among one of the highest countries in the Middle East and North Africa. $^{2}$

Diabetic retinopathy (DR) is a common diabetic complication, a recent pooled prevalence rates showed $18.5 \%$ for any retinopathy among diabetic patients. Non-proliferative diabetic retinopathy (NPDR) estimated to be $15.1 \%$ and proliferative diabetic retinopathy (PDR) $1 \% .^{3}$

Diabetic retinopathy ranked as the third leading cause for visual impairment and blindness worldwide following cataract and glaucoma. ${ }^{4}$ It is estimated that DR accounts for $4.8 \%$ of cases of blindness (37 million) worldwide, particularly in individuals aged 50 years and older. ${ }^{4}$ The prevalence of retinopathy in Saudi Arabia was aligned between $28.1 \%$ and $45.7 \%$, whereas visionthreatening diabetic retinopathy (VTDR) ranged between $4.5 \%$ and $17.5 \%$ in diabetic patients. ${ }^{5}$

Long standing poor glycemic levels beside uncontrolled of other metabolic and clinical parameters are always associated with the severity of DR. ${ }^{6}$ Therefore, DR is associated globally with hyperglycemia, hyperlipidemia, hypertension, obesity, and duration of diabetes. ${ }^{4}$ In Saudi Arabia, poor glycemic control, older age, longer diabetic duration, and the presence of other diabetic complications such as nephropathy and neuropathy have been associated with DR. ${ }^{7,8}$ However, data on DR risk factors in Saudi Arabia are limited with conflicting findings. ${ }^{6,8}$

The aim of this study is to assess the prevalence and risk factors of DR in patients with T2DM of different risks, based on the level of glycemic control.

Methods. A cross-sectional study was conducted at chronic illness clinic (CIC) between January 2019 and February 2020. The study design was approved by the local Institutional Review Board. The study was conducted according to the principles of Helsinki Declaration. We used PubMed and advanced Google scholar during search.

The current study was targeting patients with T2DM managed at the CIC, a primary healthcare canter in Riyadh, Saudi Arabia. Patients age $\geq 18$ years with T2DM (diagnosis confirmed at least 2 years prior to enrolment) and recent ( $\leq 1$ year) measurements of glycated hemoglobin (HbA1c) and retinal examination were included. Patients were excluded if they had diagnosis of T1DM, pregnancy, complications involving immunosuppression or collagenopathy, missing or 
incomplete data (more than 20\%), out of date ( $>1$ year) data, or inability or unwillingness to manage their illness and comply with medical advice.

A structural study data collection form was designs to extract data from medical records of the included patients. These included demographic and clinical characteristics; such as age, gender, body mass index (BMI), blood pressure, smoking status, duration of diabetes, use of medications, laboratory parameters, and ophthalmology screening results closest in time to $\mathrm{HbA1c}$ results. A random sample was chosen from the CIC patients in a ratio of 1:3; 101 high-risk patients and 327 low-risk patients matched on gender and diabetes duration. Patients with $\mathrm{HbA} 1 \mathrm{c}$ level $\geq 9 \%$ were classified as 'high-risk', and patients with an $\mathrm{HbAlc} \leq 7 \%$ as 'low-risk'. ${ }^{9}$ Patients were classified as non-proliferative (NPDR) or proliferative DR (PDR), with or without macular oedema $(\mathrm{MO})$ or clinically significant $\mathrm{MO}$ (CSMO), based on the international clinical disease severity criteria. ${ }^{10}$

Ophthalmological evaluation. Assessment of DR and $\mathrm{MO}$ was performed using slit lamp examination and color fundus photographs obtained through dilated pupils. All examinations were performed by trained ophthalmologists who were unaware of the patients' medical conditions, and their findings were confirmed by a fundus specialist.

Statistical analysis. The collected data were transferred and analyzed using SPSS Statistics for Windows, version 26 (IBM Corp., Armonk, N.Y., USA) ${ }^{11}$ Descriptive statistics, such as means, standard deviations were used to summarize age, BMI, SBP, DBP, low-density lipoprotein (LDL), albumin to creatinine ratio, diabetes duration and estimated glomerular filtration rate compared between the 2 groups. Percentages were used to summarize gender, smoking status, ACEi and ARB use, statin use. Also, the type and prevalence of DR among study participants; DR, NPDR, PDR, MO and CSMO. Chi squared tests were used to test the associations between different variables across high risk and low risk patients. Adjusted logistic models were used to identify the risk factors that associated with diabetic retinopathy. $P$-values $<0.05$ were considered significant. The adjusted odds ratios (aORs) with 95\% confidence interval were reported to describe the strength of these associations. Sample

Disclosure. Authors have no conflict of interests, and the work was not supported or funded by any drug company. size calculation was conducted using sample size will be calculated using Raosoft sample size calculator a trademark (confidence level of $95 \%$, margin of error of $5 \%$, and response of distribution $50 \%){ }^{12}$

Results. A total of 428 participants were included in the study. One hundred and one (23.6\%) patient were considered high-risk group. As shown in Table 1, the prevalence of DR was $88.1 \%$ in the high-risk patients, $22.1 \%$ in low-risk patients, and $37.6 \%$ in all patients. Among the low-risk patients, 68 (94.4\%) of the patients were classified as NPDR while only $4(5.6 \%)$ were classified as PDR. Among the high-risk patients, 74 $(83.1 \%)$ of the patients were classified as NPDR, while $15(16.9 \%)$ were classified as PDR. The prevalence of $\mathrm{MO}$ and CSMO were higher in the high-risk compared to low-risk patients $(15.8 \%$ versus $4.9 \%, p<0.001$ for $\mathrm{MO}$ and $7.9 \%$ versus $0.6 \%, p<0.001$ for CSMO).

Table 2 showed the demographic and clinical characteristics of the patients by risk groups. The female patients were $65.1 \%$, mean age was $61 \pm 11$ years, and the mean duration of disease was $13 \pm 7$ years. Among all variables in Table 2, only mean LDL values were significantly different between groups, being higher

Table 1 - Type and prevalence of diabetic retinopathy among study participants $(\mathrm{N}=428)$.

\begin{tabular}{|c|c|c|c|c|c|}
\hline \multirow{2}{*}{$\begin{array}{l}\text { Retinopathy type } \\
D R\end{array}$} & \multicolumn{2}{|c|}{$\begin{array}{c}\text { Low-risk } \\
(\text { HbAlc } \leq 7) \\
\text { n=327 (76.4) }\end{array}$} & \multicolumn{2}{|c|}{$\begin{array}{c}\text { High-risk } \\
(\text { HbA1c } \geq 9) \\
\mathrm{n}=101(23.6)\end{array}$} & \multirow[t]{2}{*}{$P$-value } \\
\hline & & & & & \\
\hline No & 255 & (77.9) & 12 & (11.9) & \multirow{2}{*}{$<0.001$} \\
\hline Yes & 72 & (22.1) & 89 & (88.1) & \\
\hline \multicolumn{6}{|l|}{$N P D R$} \\
\hline Mild & 34 & $(47.2)$ & 44 & (49.4) & \multirow{3}{*}{0.129} \\
\hline Moderate & 26 & (36.1) & 17 & (19.1) & \\
\hline Severe & 8 & (11.1) & 13 & (14.6) & \\
\hline \multicolumn{6}{|l|}{$P D R$} \\
\hline No & 68 & (94.4) & 74 & (83.1) & \multirow{2}{*}{0.340} \\
\hline Yes & 4 & (5.6) & 15 & (16.9) & \\
\hline \multicolumn{6}{|l|}{$M O$} \\
\hline No & 311 & (95.1) & 85 & (84.1) & \multirow{2}{*}{$<0.001$} \\
\hline Yes & 16 & $(4.9)$ & 16 & (15.8) & \\
\hline \multicolumn{6}{|l|}{ CSMO } \\
\hline No & 325 & (99.4) & 93 & (92.1) & \multirow{2}{*}{$<0.001$} \\
\hline Yes & 2 & $(0.6)$ & 8 & (7.9) & \\
\hline
\end{tabular}

Values are presented as numbers and percentages (\%). HbA1c: hemoglobin A1c, DR: diabetic retinopathy, NPDR: non-proliferative DR, PDR: proliferative DR, MO: macular oedema, CSMO: clinically significant $\mathrm{MO}$ 
in high-risk patients $(p<0.001)$. Table 3 shows the multivariate analysis for the factors that are potentially associated with DR by risk group. None of the examined factors were independently associated with DR in either group. Also, there were no difference between the adjusted odds ratio between the 2 groups.
Discussion. This cross-sectional study examined the prevalence of DR in a total of 428 high- and lowrisk T2DM patients, stratified based on HbA1c levels $\geq 9$ and $\leq 7$ respectively, who were treated at a primary healthcare canter. The prevalence of DR was $88.1 \%$ $(p<0.001)$ in the high-risk patients, $22.1 \%(p<0.001)$ in

Table 2 - Comparison of baseline demographics and clinical characteristics of the participants $(\mathrm{N}=428)$.

\begin{tabular}{|c|c|c|c|c|c|}
\hline \multirow[t]{2}{*}{ Variables } & \multicolumn{2}{|c|}{$\begin{array}{c}\text { Low-risk } \\
(\text { HbA1c } \leq 7)\end{array}$} & \multicolumn{2}{|c|}{$\begin{array}{c}\text { High-risk } \\
(\text { HbA1c } \geq 9)\end{array}$} & \multirow[t]{2}{*}{$P$-value } \\
\hline & \multicolumn{2}{|c|}{ Mean \pm SD } & \multicolumn{2}{|c|}{$\operatorname{Mean} \pm S D$} & \\
\hline Age (years) & \multicolumn{2}{|c|}{$61.3 \pm 11.5$} & \multicolumn{2}{|c|}{$60.1 \pm 10.1$} & 0.327 \\
\hline BMI $\left(\mathrm{kg} / \mathrm{m}^{2}\right)$ & \multicolumn{2}{|c|}{$32.6 \pm 7.0$} & \multicolumn{2}{|c|}{$33.6 \pm 6.6$} & 0.279 \\
\hline $\mathrm{SBP}(\mathrm{mmHg})$ & \multicolumn{2}{|c|}{$125.9 \pm 16.2$} & \multicolumn{2}{|c|}{$126.6 \pm 16.8$} & 0.683 \\
\hline $\mathrm{DBP}(\mathrm{mmHg})$ & \multicolumn{2}{|c|}{$65.6 \pm 10.7$} & \multicolumn{2}{|c|}{$65.5 \pm 11.0$} & 0.944 \\
\hline $\mathrm{LDL}(\mathrm{mmol} / \mathrm{L})$ & \multicolumn{2}{|c|}{$2.34 \pm 0.79$} & \multicolumn{2}{|c|}{$2.75 \pm 0.98$} & $<0.001$ \\
\hline Albumin to creatinine ratio & \multicolumn{2}{|c|}{$12.3 \pm 39.7$} & \multicolumn{2}{|c|}{$16.6 \pm 67.8$} & 0.599 \\
\hline Diabetes duration (years) & \multicolumn{2}{|c|}{$13.2 \pm 7.2$} & \multicolumn{2}{|c|}{$13.3 \pm 7.2$} & 0.886 \\
\hline eGFR $\left(\mathrm{ml} / \mathrm{min} / 1.73 \mathrm{~m}^{2}\right)$ & \multicolumn{2}{|c|}{$85.07 \pm 22.39$} & \multicolumn{2}{|c|}{$87.21 \pm 24.95$} & 0.451 \\
\hline \multicolumn{6}{|l|}{ Gender } \\
\hline Male & 114 & $(34.9)$ & (35) & $(34.7)$ & \multirow{2}{*}{0.969} \\
\hline Female & 213 & $(65.1)$ & 66 & $(65.3)$ & \\
\hline \multicolumn{6}{|l|}{ Smoker } \\
\hline No & 309 & $(96.9)$ & 96 & $(97.0)$ & \multirow{2}{*}{0.958} \\
\hline Yes & 10 & $(3.1)$ & 3 & $(3.0)$ & \\
\hline \multicolumn{6}{|l|}{$A C E i$ and $A R B$ use } \\
\hline No & 68 & $(22.0)$ & 25 & $(25.8)$ & \multirow{2}{*}{0.441} \\
\hline Yes & 241 & $(78.0)$ & 72 & $(74.2)$ & \\
\hline \multicolumn{6}{|l|}{ Statin use } \\
\hline No & 25 & $(8.1)$ & 3 & $(3.1)$ & \multirow{2}{*}{0.093} \\
\hline Yes & 283 & (91.9) & 93 & $(96.9)$ & \\
\hline
\end{tabular}

Values are presented as numbers and percentages (\%). BMI: body mass index; SBP: systolic blood pressure, DBP: diastolic blood pressure, LDL: low-density lipoprotein, eGFR: estimated glomerular filtration rate, ACEI: angiotensin converting enzyme inhibitors, ARBs: angiotensin-receptor blockers

Table 3 - Multivariate analysis for the factors that are potentially associated with diabetic retinopathy by risk group.

\begin{tabular}{|c|c|c|c|c|c|c|c|c|}
\hline & \multicolumn{4}{|c|}{$\begin{array}{c}\text { Low-risk } \\
(\text { HbA1c } \leq 7)\end{array}$} & \multicolumn{4}{|c|}{$\begin{array}{c}\text { High-risk } \\
(\text { HbA1c } \geq 9)\end{array}$} \\
\hline & aOR & $\begin{array}{c}\text { Lower } \\
\text { CI }\end{array}$ & $\begin{array}{l}\text { Upper } \\
\text { CI }\end{array}$ & $P$-value & $\mathrm{aOR}$ & $\begin{array}{c}\text { Lower } \\
\text { CI }\end{array}$ & $\begin{array}{l}\text { Upper } \\
\text { CI }\end{array}$ & $P$-value \\
\hline Age & 1.012 & 0.990 & 1.036 & 0.284 & 0.970 & 0.911 & 1.033 & 0.338 \\
\hline BMI & 1.014 & 0.968 & 1.061 & 0.566 & 1.021 & 0.917 & 1.137 & 0.701 \\
\hline Gender & 0.611 & 0.359 & 1.040 & 0.069 & 1.123 & 0.304 & 4.151 & 0.862 \\
\hline SBP & 1.008 & 0.992 & 1.024 & 0.340 & 0.996 & 0.959 & 1.034 & 0.825 \\
\hline DBP & 0.988 & 0.964 & 1.013 & 0.340 & 1.028 & 0.967 & 1.094 & 0.375 \\
\hline HbA1c (last 12 months) & 0.712 & 0.383 & 1.321 & 0.281 & 1.096 & 0.645 & 1.863 & 0.733 \\
\hline LDL & 1.007 & 0.712 & 1.423 & 0.970 & 1.145 & 0.564 & 2.328 & 0.708 \\
\hline Albumin to creatinine ratio & 0.993 & 0.972 & 1.014 & 0.485 & 1.225 & 0.781 & 1.923 & 0.377 \\
\hline Diabetes duration & 1.025 & 0.989 & 1.062 & 0.173 & 0.998 & 0.915 & 1.090 & 0.972 \\
\hline ACEI/ARB use & 0.819 & 0.416 & 1.609 & 0.562 & 1.524 & 0.305 & 7.626 & 0.608 \\
\hline Annual eGFR & 0.997 & 0.985 & 1.009 & 0.593 & 0.992 & 0.965 & 1.020 & 0.555 \\
\hline
\end{tabular}


low-risk patients, and $37.6 \%$ in all patients. The overall DR prevalence in the current study was comparable to previous studies estimating DR between 28.1\% and $45.7 \%$ of diabetic patients in Saudi Arabia., Additionally, the observed higher prevalence in high-risk patients was similar the prevalence estimated by Magliah et $\mathrm{al}^{6}$ in Jeddah, Saudi Arabia where DR was diagnosed of high-risk diabetic patients in $86.8 \%$ and of low-risk diabetic patients in $13.2 \%$.

In the present study, the total numbers of $\mathrm{MO}$ case was $32(7.5 \%)$ and CSMO case was $10(2.3 \%)$ $(p<0.001)$. However, Martinell et $\mathrm{al}^{13}$ reported an MO prevalence of $11 \%$ at the time of DM diagnosis in a Swedish population. These discrepancies in prevalence between studies might be accounted by genetic differences between populations; for example, Tan et $\mathrm{al}^{14}$ have shown that individual of Malays and Chinese descent are less likely to develop DR and MO compared to Indian and Singapore.

Glycated hemoglobin A1c and LDL levels in the current study were strongly associated with DR risk in the bivariate analysis $(p<0.001)$. The observed strong association of DR with $\mathrm{HbA1c}$ was consistent in all previous local ${ }^{6,7}$ and international studies. ${ }^{4}$ Evidence shows that an increased rate of DR is more closely associated to LDL than to other lipid profile parameters, such as high-density lipoprotein, total cholesterol, or triglycerides. ${ }^{15}$ Therefore, IDF recommends glycemic control and lipid profile management to delay DR progression. ${ }^{2}$ This can be achieved by patient compliance with recommended medications and scheduled visits.

Study limitations. The current study used a comprehensive data for DR prevalence and risk factors. Nevertheless, some limitations are acknowledged. Being a single primary care centre, the generalisability should be limited to similar population. In addition, data on BMI, smoking status, and ACE inhibitors and ARBs use were missing from several patient records, which might have affected the results. Despite reporting the MO prevalence in our study, we were unable to account for its classification due to the lack of relevant data.

In conclusion, among a sample of patients with an average 13 years of T2DM managed at a primary care centre in Saudi Arabia, the prevalence of DR was 88.1\% in the high-risk patients, $22.1 \%$ in low-risk patients, and $37.6 \%$ in all patients. High HbA1c and LDL levels were associated with higher DR risk. Larger multicentre studies with longitudinal data may be required to assess the risk factors associated with DR progression.

Acknowledgment. The authors would like to thank Dr. Farooq A. Bodla for his help in performing ophthalmology screening,
Ms. Reuof A. Bushnag and Ms. Jancy Thomson for their help in recruiting participants, data collection and providing technical help. We also would like to thank Elsevier (www.elsevier.com) for English language editing.

Received 7th January 2021. Accepted 19th April 2021.

From the Family and Community Medicine Department (Alghamdi, Tourkmani, Alharbi, Alrasheed), Chronic Illness Center, Prince Sultan Military Medical City; and Biostatistician (Almadani), National Center of Evidence Based Health Practice, Saudi Health Council, Riyadh, Kingdom of Saudi Arabia.

Address correspondence and reprints request to: Dr. Ayla M. Tourkmani, Department of Family Medicine, Prince Sultan Military Medical City, Riyadh, Kingdom of Saudi Arabia.E-mail: aylatourkmani@gmail.com

ORCID ID: https://orcid.org/0000-0002-6060-7141

\section{References}

1. Saeedi P, Petersohn I, Salpea P, Malanda B, Karuranga S, Unwin N, et al. IDF Diabetes Atlas Committee. Global and regional diabetes prevalence estimates for 2019 and projections for 2030 and 2045: Results from the International Diabetes Federation Diabetes Atlas, 9th edition. Diabetes Res Clin Pract 2019; 157: 107843.

2. International Diabetes Federation. Diabetes Atlas, 9th ed. (Updated 2019. Accessed 2021 January 1). Available from URL: https:/www.diabetesatlas.org/en/

3. Cheloni R, Gandolfi SA, Signorelli C, Odone A. Global prevalence of diabetic retinopathy: protocol for a systematic review and meta-analysis. BMJ Open 2019; 9: e022188.

4. Ting DS, Cheung GC, Wong TY. Diabetic retinopathy: global prevalence, major risk factors, screening practices and public health challenges: a review. Clin Exp Ophthalmol 2016; 44: 260-277.

5. Al-Ghamdi AS. Adults visual impairment and blindness - An overview of prevalence and causes in Saudi Arabia. Saudi J Ophthalmol 2019; 33: 374-381.

6. Magliah SF, Bardisi W, Al Attah M, Khorsheed MM. The prevalence and risk factors of diabetic retinopathy in selected primary care centers during the 3-year screening intervals. $J$ Family Med Prim Care 2018; 7: 975-981.

7. Yasir ZH, Hassan AD, Rajiv K. Diabetic retinopathy (DR) among 40 years and older Saudi population with diabetes in Riyadh governorate, Saudi Arabia - A population based survey. Saudi J Ophthalmol 2019; 33: 363-368.

8. Ahmed RA, Khalil SN, Al-Qahtani MA. Diabetic retinopathy and the associated risk factors in diabetes type 2 patients in Abha, Saudi Arabia. J Family Community Med 2016; 23 : 18-24.

9. Sherwani SI, Khan HA, Ekhzaimy A, Masood A, Sakharkar MK. Significance of HbA1c Test in diagnosis and prognosis of diabetic patients. Biomark Insights 2016; 11: 95-104.

10. Duh EJ, Sun JK, Stitt AW. Diabetic retinopathy: current understanding, mechanisms, and treatment strategies. JCI Insight 2017; 2: e93751.

11. IBM Corp N. IBM SPSS statistics for windows. IBM Corp, Armonk, NY. 2010. [Updated 2021. Accessed 2019]. Available from: https://www.ibm.com/support/pages/how-cite-ibm-spssstatistics-or-earlier-versions-spss

12. Raosoft. Raosoft Sample Size Calculator. [Updated 2004. Accessed 2020]. Available from: http://www.raosoft.com/ samplesize.html 
13. Martinell M, Dorkhan M, Stålhammar J, Storm P, Groop L, Gustavsson C. Prevalence and risk factors for diabetic retinopathy at diagnosis (DRAD) in patients recently diagnosed with type 2 diabetes (T2D) or latent autoimmune diabetes in the adult (LADA). J Diabetes Complications 2016; 30 : 1456-1461.
14. Tan GS, Gan A, Sabanayagam C, Tham YC, Neelam K, Mitchell P, et al. Ethnic differences in the prevalence and risk factors of diabetic retinopathy: the Singapore epidemiology of eye diseases study. Ophthalmology 2018; 125: 529-536.

15. Zhou Y, Wang C, Shi K, Yin X. Relationship between dyslipidemia and diabetic retinopathy: A systematic review and meta-analysis. Medicine (Baltimore) 2018; 97: e12283. 